\title{
DOES METACOGNITIVE KNOWLEDGE ABOUT EXPLANATION MODERATE THE EFFECT OF EXPLANATION EXPECTANCY?
}

\author{
Tatsushi FUKAYA \\ Japan Society of Promotion of Science, Hosei University, Japan
}

\begin{abstract}
Prior studies have investigated whether the expectation that one will explain materials promotes text comprehension during learning. Such research, however, has had inconsistent results, which suggests that the effects of explanation expectancy depend on individual difference factors. In the present study, an experiment with 8th-grade students examined whether their metacognitive knowledge about explanation (elaborative explaining orientation) moderated the effects of explanation expectancy on text comprehension. Before studying the text, students in the experimental condition were instructed that they would have to explain the content of the text to another person. All the students then read the text, and answered test questions. Students in the experimental group had low text comprehension scores, but only for students with low orientation to elaborate and organize a passage when explaining. The findings demonstrated that moderating factors including metacognitive knowledge about explanation could cause the inconsistent results of previous research.
\end{abstract}

Key words: explanation expectancy, metacognitive knowledge about explanation, elaborative explaining orientation, text comprehension, moderation

\section{INTRODUCTION}

Individuals serving as tutors in peer-tutorial programs can derive benefits from explaining learning materials (for a meta-analysis see Cohen, Kulik, \& Kulik, 1982). This learning gain has been referred to as the tutor-learning effect (Roscoe \& Chi, 2007) and has received much research attention (e.g., Plötzner, Dillenbourg, Preier, \& Traum, 1999; Roscoe \& Chi, 2007). However, the magnitude of the tutor-learning effect that has been observed in these studies is somewhat low. Indeed, Cohen et al. (1982) found that the effect size $d$ for tutor learning was .33, which is small according to Cohen's (1969) criteria. It is thus important to clarify the factors that promote tutor learning in order to maximize the potential benefits.

One possible factor of the tutor-learning effect is preparation for explanation. In

Appreciation is expressed to Shin-ichi Ichikawa for his helpful comments on an earlier version of this article and Masako Tanaka for assistance with development of experimental materials. This research was supported in part by grant from Research Fellow of the Japan Society for the Promotion of Science (23-9955) and Center for Excellence of School Education, Graduate School of Education, The University of Tokyo.

Correspondence concerning this article should be addressed to Tatsushi Fukaya, Department of Psychology, Hosei University, 3-16-21-202 Komagome, Toshima-ku, Tokyo 170-0003, Japan (e-mail: fuka1026@gmail.com). 
other words, the tutor-learning effect may be attributable not only to the activity of explaining itself, but also to the process of reading material in the expectation that one will explain the content later. This is referred to here as "explanation expectancy." Several studies have reported empirical evidence of the beneficial effect of explanation expectancy (Annis, 1983; Bargh \& Schul, 1980; Benware \& Deci, 1984; Fiorella \& Mayer, 2013; Sugie \& Kajita, 1989). However, this enhancement has not been consistently demonstrated in other studies that have manipulated expectancy (Ehly, Keith, \& Bratton, 1987; Fukaya, 2013; Ito \& Kakihana, 2009; Renkl, 1995; Schommer, Crouse, \& Rhodes, 1992), and the reasons for these inconsistent results are quite unclear (Renkl, 1995).

The inconsistent effect of explanation expectancy might be caused by moderating variables. Moderating variables refer to factors that change the direction or magnitude of the independent variable's influence (Baron \& Kenny, 1986). If the effect of explanation expectancy were moderated by individual or situation variables, overall findings would be inconsistent with some research reporting positive effects and others reporting no effects. That is why the inconsistent findings of prior research suggest that researchers need to focus on the possible moderating factor causing the individual or situational difference of the effect. As Roscoe and Chi (2007) suggested, whether tutors could benefit from tutoring depends on the learning processes. Moreover, prior research has emphasized the role of learners' metacognitive knowledge as a factor affecting this process. Thus, we examine whether the learner's metacognitive knowledge about explanation, especially elaborative explaining orientation, would moderate the impact of explanation expectancy. In the following section, the rational for this idea is described.

\section{The Importance of Metacognitive Knowledge about Explanation as an Individual Difference Factor}

Metacognitive knowledge is defined as knowledge that has to do with diverse cognitive tasks, goals, actions, and experiences (Flavell, 1979). Flavell (1979) classified metacognitive knowledge into three components: knowledge regarding cognitive nature of human beings (person variable), knowledge about the demands of information processed (task variable), and knowledge about effective strategies to guide or control learning processes (strategic variable). Especially, skilled learners hold the knowledge about effective strategies to accomplish a given task proficiently. Citing Weinstein and Mayer (1986), Pintrich (2002) outlined the metacognitive knowledge about effective strategies into two subcategories: elaboration and organization. Elaboration refers to cognitive operation to integrate the material with his or her prior knowledge and make inferences for implicit information. Organization is to clarify the connections between content elements.

There is also accumulated evidence that conceptions of learning play important roles in the use of these learning strategies (e.g., Purdie, Hattie, \& Douglas, 1996). Conceptions of learning are system of abstract beliefs about how learning occurs and one of the components of metacognitive knowledge (Uesaka, 2010). For example, Ichikawa and colleagues reported that conceptions of learning could be distinguished between elaborative memorizing orientation and rote memorizing orientation (Ichikawa, Horino, \& Kubo, 1998; Uesaka, Seo, \& Ichikawa, 2008). The former refers to the belief that learning 
is to understand the meaning of the materials. On the other hand, the latter refers to the belief that learning is to memorize the material without understanding. Therefore elaborative memorizing orientation is hypothesized to promote a use of learning strategies such as elaboration and organization. Prior studies have reported results supporting this idea (e.g., Dart et al., 2000; Suzuki, 2013).

Another important aspect of metacognitive knowledge is its domain or task specificity. Borkowski, Milstead, and Hale (1988) suggested that metacognitive knowledge is assumed to structure hierarchically from specific task level to general level across specific tasks. In fact, previous research has examined the function of domain or task specific metacognitive knowledge such as reading (Mokhtari \& Reichard, 2002), writing (Sakihama, 2003), and science (Solomon, Scott, \& Duveen, 1996). Thus we can also assume that there are various conceptions or beliefs at task specific level. In this study, we focused on conceptions of explaining, especially elaborative explaining orientation, which is defined as orientation for explanation elaborating upon one's prior knowledge and organizing ideas across topics. Elaborative explaining orientation is orientation for knowledge-building explanation, which Roscoe and Chi (2007) proposed as effective explanation, and also conceptualized as a factor causing individual differences in the effect of explanation expectancy.

According to Efklides (2011), perceiving the task at hand would activate metacognitive knowledge and activated knowledge would guide the following strategic processing when performing the task. As mentioned above, elaborative explaining orientation forms one of the components of metacognitive knowledge. Thus, explanation expectancy might also activate elaborative explaining orientation, which regulates our use of strategies when preparing explanation. This means that elaborative explaining orientation might be one of potential factors, leading to the individual differences of the explanation expectancy effect. In particular, efficient tutors with high elaborative explaining orientation make inferences for authors' implicit claims in the text or organize the content of texts to be logically coherent, in order to subsequently explain the learned contents effectively. In contrast, if students have low elaborative explaining orientation, explanation expectancy might interfere with their learning by prompting the use of ineffective strategies, such as rote learning without elaborating or organizing.

\section{The Present Study}

Given these theoretical and empirical bases, we try to discover whether students' elaborative explaining orientation moderates the effect of explanation expectancy. To measure elaborative explaining orientation, we requested participants to respond to a selfreport scale before the experimental session. Although using self-report scales for assessing cognitive tasks has sometimes been criticized, due to their low validity (e.g., Cromley \& Azevedo, 2006), it has also been reported that self-report scales assessing strategy perceptions in the context of a specific task have more validity than those assessing global functions (Samuelstuen \& Bråten, 2007). Additionally, a number of previous studies have used self-report scales to measure conceptions of learning and have reported on the relationship between such conceptions and task performance (e.g., Purdie 
et al., 1996). These considerations justify our use of self-reports to assess students' conceptions of explaining.

In our study, 8th-grade students participated and half the students studied a text material with explanation expectancy. To date, the majority of studies examining the explanation expectancy effect have been conducted with college students as participants (e.g., Bargh \& Schul, 1980). However, because peer-tutoring or explanation activity are also implemented in primary and secondary school (e.g., Cohen et al., 1982), we need to focus on the effect on students other than at the college level. In addition, the present study controlled the effect of differences in the schools (public school vs. school attached to a university), by treating it as a covariate. In the Japanese education system, most students of secondary school attend public schools, but a small number of students attend secondary schools that are attached to universities ${ }^{1}$. Students in schools attached to universities generally have higher academic achievements compared to those in public schools. This is a factor that confounds the results of the experimental manipulations. Therefore, this variable was controlled in this study.

We developed two types of tests to investigate the effect of explanation expectancy on text representation. The first and primary measure used in the study was multiplechoice comprehension tests. In order to respond to these questions, it was necessary to make inferences about implicit information. On the other hand, the fill-in-blank question was used for assessing verbatim text representation. We hypothesized that there is an interaction between explanation expectancy and elaborative explaining orientation only in the case of multiple-choice comprehension tests. Conversely, the moderating effect of elaborative explaining orientation would not be observable on verbatim memory tests, because deep learning strategies such as organization and elaboration would involve the process of constructing comprehension-level representations, not memory-level representations (cf. Kintsch, 1994).

\section{METHOD}

\section{Participants}

The participants in this study were 51 Japanese 8th-grade students who took part in a five-day seminar on learning skills held at the University of Tokyo. The seminar was conducted by graduate students in educational psychology and included several subjects, such as mathematics and social studies. During our recruiting process, we informed school teachers about the seminar. The students voluntarily participated in the seminar, and their parents provided consent for their children's participation. Participants took part in classes on several subjects, and each class focused on a different learning skill (e.g., English listening skills). The experiment was conducted during the first day of the seminar in the class on language arts (i.e., Japanese). Participants were randomly assigned to one of two conditions. Half of the participants expected to explain the content after reading a text $(n=25,10$ males and 15 females $)$, and half did not $(n=26,12$

${ }^{1}$ There are some differences between public schools and schools attached to universities. First, many schools attached to universities conduct an entrance examination, so that the students tend to attain high academic performance. Second, while schools' curricula of both public and non-public schools are closely supervised by the Ministry of Education in Japan, curriculum of schools attached to universities tends to be unique with an emphasis, for example, on the interdisciplinary classes. 
males and 14 females). The number of students from the university secondary school was not significantly different in either group (5 participants in the experimental group, and 8 in the control group, Fisher's exact test, $p=.52, n s$.$) .$

\section{Materials}

Elaborative explaining orientation. Roscoe and Chi (2007) argued that effective explanation, namely knowledge-building explanation, are explanations that elaborate one's own prior knowledge and integrate ideas coherently. With this theoretical basis in mind, we generated a set of four items to measure each student's elaborative explaining orientation in their daily classroom lessons in language arts. When generating these items, we also referred to prior research on conceptions of learning (e.g., Ichikawa et al., 1998; Uesaka et al., 2008) in regard with items' expression. The four items consisted of "A good explanation is one that organizes the learned material to be easily comprehensible," "An important thing in explanation is to paraphrase difficult content in order to be easily understood," "It is important to elaborate the description in the lesson if that helps the tutee's understanding," "One should restate original ideas in one's own words in order to explain clearly." These items were included in a pre-questionnaire, requiring participants to rate how well they agreed with the descriptions. All four items used a 5-point scale, ranging from 1 (not at all true) to 5 (very true). These individual scores were added up to obtain a total score, then divided by the number of items to get an average score. The reliability was quite high, with a Cronbach's alpha of .81 .

Learning materials. Two passages were used in this study to confirm generalizability of results, and participants read one text. Each passage consisted of about 25 sentences with around 1,100 Japanese characters and letters. The passages were divided into several paragraphs and printed on four separate sheets of paper. One of the texts discussed how human beings are affected by art (Toyama, 2003) and the other described technical developments in Japan during the Edo period (Ishii, 1997). These passages were taken from a language arts workbook at the secondary school level. The passages were not encyclopedic in style, but rather included the authors' ideas and arguments (see Appendix A for an example text). The two texts were randomly assigned in both the experimental and control conditions. These materials, as well as the learning outcome measures, were pilot tested with a graduate student majoring in educational psychology and were modified for clarity on the basis of the feedback.

Learning outcome measures. Learning outcomes were assessed in two ways. Participants were tested on the material using verbatim memory and comprehension tests. The verbatim memory tests were eight fillin-blank questions designed to assess verbatim recall of information explicitly stated in the text. Six 6alternative multiple-choice questions were developed as comprehension tests, which tapped thematic information and required elaborative inferences from the passage (see Britton \& Gülgöz, 1991, for details about the creation of inferential questions). Examples of test questions are shown in Appendix B. In both measures, each question was worth one point.

\section{Procedure}

About one month before the learning skills seminar, pre-questionnaires about attending school and elaborative explaining orientation were mailed to students and their parents. On the first day of the learning skills seminar, which was conducted in a university seminar room, booklets including instructions, the text to be studied, and the post-tests were given to all participants. Participants in both groups were told that they would be tested on the material after studying it. In addition, participants in the experimental condition were informed that after studying the material, they would write an expository essay to explain the learned content to an imaginary 6th-grade student. We chose 6th-grade students as readers because Gunel, Hand, and McDermott (2009) showed that explaining for younger students improves understanding compared to explaining for teacher or parents. Participants in the control group were not told this. All students then studied the text for 20 minutes. Next, they took the two-part post-tests for 13 minutes. Finally, all were asked to write an expository essay to explain the learned content to an imaginary 6th-grade student ${ }^{2}$. The overall sessions took 50 minutes.

\footnotetext{
${ }^{2}$ Although participants were asked to write an expository essay, there was insufficient time for them to complete the task, because in the five-day seminar the entire session of each day ended in 50 minutes. Thus, it was assumed that their essays were invalid and they were excluded from the data analysis.
} 


\section{RESULTS}

Test questions were scored by tabulating the number of correct answers. Maximum scores for the comprehension and verbatim memory tests were 6 and 8 , respectively. Although the influence of text type on study measures was examined to assess main effects and interactional effects with explanation expectancy, all effects were found to be non-significant $\left(F_{\mathrm{S}}<1.5\right)$. The text variable was therefore excluded from the following analyses. Table 1 shows descriptive statistics for the scores of the measures used.

A question of interest for this study was whether the effects of explanation expectancy were moderated by students' elaborative explaining orientation. To address this question, we used a hierarchical regression analysis, as recommended by Aiken and West (1991), to analyze the moderating effect. For this purpose, the experimental conditions were dummy coded into one variable that represented the effect of explanation expectancy (without explanation expectancy $=0$, with expectancy $=1$ ). This dummy variable was also multiplied by elaborative explaining orientation to compute a corresponding interaction term. In conducting this, elaborative explaining orientation was mean-centered to minimize problems of multicollinearity (Cronbach, 1987). School difference was also dummy coded such that it represents the effect of attending secondary school attached to a university (public school $=0$, school attached to a university $=1$ ). Hierarchical regression analysis was conducted with explanation expectancy, elaborative explaining orientation, and school difference entered in step 1, and the interaction term in step 2.

\section{Comprehension tests}

The results from the hierarchical regression analyses of text comprehension scores are presented in Table 2. In step 1, independent variables other than the school difference did not predict text comprehension scores. The most important finding is that the interaction term of explanation expectancy $\times$ elaborative explaining orientation added a significant amount of explained variance in step $2, \Delta R^{2}=.09, F(1,46)=5.96, p=.02$. This interaction effect is illustrated in Fig. 1.

We then conducted simple slope analysis to probe the nature of interaction (Aiken \&

Table 1. Descriptive and Inferential Statistics for Study Measures

\begin{tabular}{|c|c|c|c|c|c|}
\hline \multirow{2}{*}{ Variable (Range of possible score) } & \multicolumn{2}{|c|}{$\begin{array}{l}\text { Experimental group } \\
\qquad(n=25)\end{array}$} & \multicolumn{2}{|c|}{$\begin{array}{l}\text { Control group } \\
\quad(n=26)\end{array}$} & \multirow{2}{*}{$\begin{array}{l}t \text { scores } \\
(d f=49)\end{array}$} \\
\hline & $M$ & $S D$ & $M$ & $S D$ & \\
\hline Elaborative explaining orientation (1-5) & 3.79 & 0.66 & 3.79 & 0.71 & 0.03 \\
\hline Verbatim memory test $(0-8)$ & 2.72 & 1.51 & 3.23 & 1.27 & 1.31 \\
\hline Comprehension test $(0-6)$ & 2.60 & 1.19 & 2.96 & 1.46 & 0.97 \\
\hline
\end{tabular}

Note. None of $t$ scores were statistically significant. 
Table 2. Hierarchical Regression Results for the Effects of Explanation Expectancy and Elaborative Explaining Orientation on Text Comprehension

\begin{tabular}{|c|c|c|c|c|}
\hline \multirow{2}{*}{ Variable } & \multicolumn{2}{|c|}{ Step 1} & \multicolumn{2}{|c|}{ Step 2} \\
\hline & $b$ & $b S E$ & $b$ & $b S E$ \\
\hline \multicolumn{5}{|l|}{ Step 1} \\
\hline Explanation expectancy & -0.24 & 0.35 & -0.23 & 0.33 \\
\hline Elaborative explaining orientation & 0.43 & 0.26 & -0.11 & 0.33 \\
\hline School difference & $1.09^{* *}$ & 0.40 & $1.17^{* *}$ & 0.38 \\
\hline \multicolumn{5}{|l|}{ Step 2} \\
\hline \multicolumn{3}{|c|}{ Explanation expectancy $\times$ Elaborative explaining orientation } & $1.20 *$ & 0.49 \\
\hline$\Delta R^{2}$ & \multicolumn{2}{|c|}{.19} & \multicolumn{2}{|c|}{.09} \\
\hline $\operatorname{Adj} R^{2}$ & \multicolumn{2}{|c|}{.14} & \multicolumn{2}{|c|}{.22} \\
\hline
\end{tabular}

$* p<.05 . * * p<.01$.

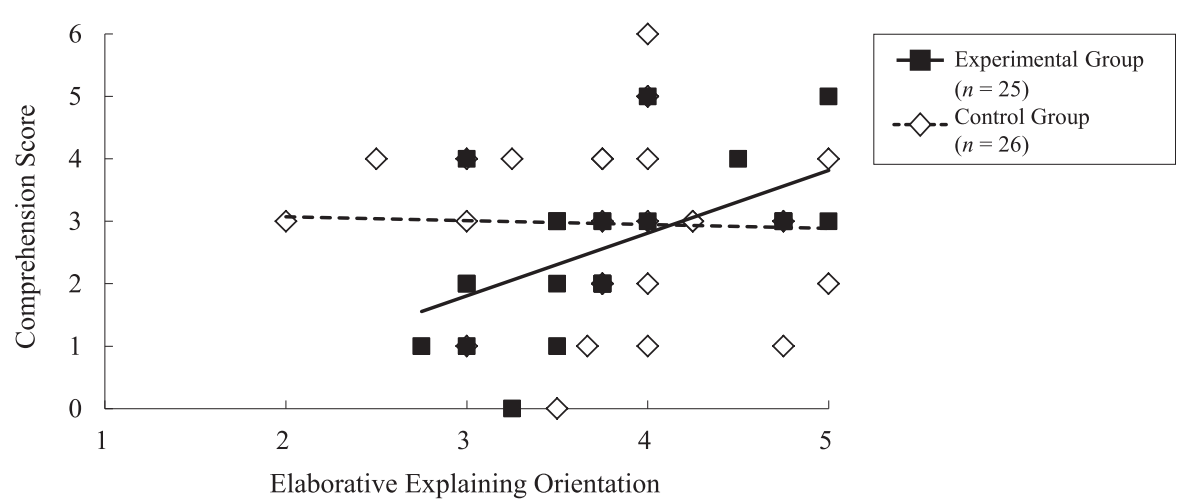

Fig. 1. Text comprehension as a function of explanation expectancy and elaborative explaining orientation. Note. The two lines on the plot represent regression lines for the two groups.

West, 1991). This examines the regression slopes (simple slopes) for the independent variable (explanation expectancy) at lower $(M-1 S D)$ and higher $(M+1 S D)$ levels of the moderator (elaborative explaining orientation). As elaborative explaining orientation is higher, the influence of explanation expectancy was not significant $(b=0.57, S E b=0.47$, $p=.23$ ). On the other hand, when elaborative explaining orientation is lower, explanation expectancy negatively predicted comprehension test scores $(b=-1.04, S E b=0.47$, $p=.03$ ). We additionally conducted the Johnson-Neyman analysis to calculate the scores of moderator that yields the significant simple slope (for a detailed description of this analysis, see Preacher, Curran, \& Bauer, 2006). The results of the Johnson-Neyman analysis indicated that for elaborative explaining orientation of 3.30 or below, students with explanation expectancy had significantly lower comprehension test scores than those in the control group $(p<.05)$. 
Table 3. Hierarchical Regression Results for the Effects of Explanation Expectancy and Elaborative Explaining Orientation on Text Verbatim Memory

\begin{tabular}{|c|c|c|c|c|}
\hline \multirow{2}{*}{ Variable } & \multicolumn{2}{|c|}{ Step 1} & \multicolumn{2}{|c|}{ Step 2} \\
\hline & $b$ & $b S E$ & $b$ & $b S E$ \\
\hline \multicolumn{5}{|l|}{ Step 1} \\
\hline Explanation expectancy & -0.56 & 0.37 & -0.55 & 0.37 \\
\hline Elaborative explaining orientation & $0.75^{* *}$ & 0.27 & 0.53 & 0.37 \\
\hline School difference & -0.46 & 0.42 & -0.42 & 0.43 \\
\hline \multicolumn{5}{|l|}{ Step 2} \\
\hline \multicolumn{3}{|c|}{ Explanation expectancy $\times$ Elaborative explaining orientation } & 0.48 & 0.55 \\
\hline$\Delta R^{2}$ & \multicolumn{2}{|c|}{.19} & \multicolumn{2}{|c|}{.01} \\
\hline $\operatorname{Adj} R^{2}$ & \multicolumn{2}{|c|}{.14} & \multicolumn{2}{|c|}{.13} \\
\hline
\end{tabular}

$* * p<.01$.

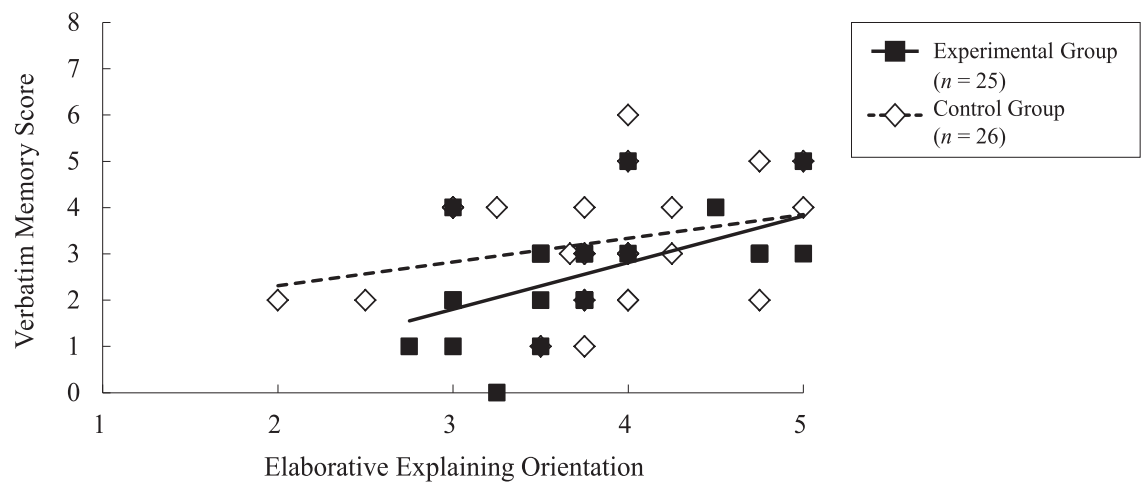

Fig. 2. Text memory as a function of explanation expectancy and elaborative explaining orientation. Note. The two lines on the plot represent regression lines for the two groups.

\section{Verbatim Memory tests}

We repeated the same set of analyses on the verbatim memory test scores (see Table 3). There was a significant effect of elaborative explaining orientation in step 1. The regression coefficient demonstrated an enhancement effect, meaning a positive relationship between elaborative explaining orientation and memory test performance. However, the interaction term between explanation expectancy and elaborative explaining orientation was not significant in step $2, \Delta R^{2}=.01, F(1,46)=0.78, p=.38$. Fig. 2 showed the scatter plot of the scores of verbatim memory tests. 


\section{DISCUSSION}

The primary goal of this study was to analyze the moderating effects of elaborative explaining orientation by comparing the impact of elaborative explaining orientation on text comprehension with or without explanation expectancy. The data supported the hypothesis that comprehension scores regressed on participants' elaborative explaining orientation in the experimental group but not in the control group. This means that the effects of explanation expectancy depend on the individual difference factor. Thus, the findings support the view that the inconsistent results of previous research on explanation expectancy (e.g., Annis, 1983; Ehly et al., 1987) could have been caused by moderating factors including elaborative explaining orientation.

The results of simple slope analysis revealed that explanation expectancy disrupted text comprehension for participants with low elaborative explaining orientation. Without metacognitive knowledge about effective strategies for explanation, they would process a text superficially, using ineffective reading strategies such as rote learning without elaboration. In such cases, the negative effect of explanation expectancy could be mediated by the use of inefficient reading strategies. Therefore a fruitful step following this study would be to investigate the learning processes of such individuals directly by, for instance, analyzing think-aloud protocols recorded during reading (cf. Pressley \& Afflerbach, 1995).

On the other hand, for students with high elaborative explaining orientation, explanation expectancy did not have a significant impact on their text comprehension. However, it should be noted that the sign of the regression coefficient representing explanation expectancy was positive for these individuals. Thus, the non-significant effect of explanation expectancy could have been due to the small number of participants in this study. Given the limits of this study, further research should be carried out to explore the possibility that requiring students with high elaborative explaining orientation to prepare an explanation promotes text comprehension.

A related question is why there was no moderation of explanation expectancy by elaborative explaining orientation on verbatim memory tests. It is probable that no moderation on memory test reflects differences between the two tests that measure other aspects of reading processes. Elaborative explaining orientation exerts its influence on the process of constructing comprehension-level representation, because organization and elaboration strategies allow them to integrate ideas in different parts of a text or make inferences about authors' implicit claims. In contrast, the memory test questions measured the verbatim recall of information in the text. Thus, participants who did well on the comprehension test did not necessarily show high achievement in the memory test.

Elaborative explaining orientation, however, was positively related to verbatim memory performance, regardless of explanation expectancy. This result is inconsistent with the assumption that elaborative explaining orientation is activated only in taskspecific contexts (i.e., preparing and generating an explanation). This may be because elaborative explaining orientation co-varies with other variables that influence the performance of verbatim memory tests, although we could not specify what these factors 
would be in this study. Thus, it remains for future studies to pinpoint the exact nature of this result in terms of the relationship between elaborative explaining orientation and other variables related to reading processes.

The results generally supported our hypothesis that individual differences in explanation expectancy depend on elaborative explaining orientation. However, other explanations of these results are also possible. For example, these results could be explained by anxiety for later explanation. Renkl (1995) showed that explanation expectation significantly enhanced state anxiety during learning (but only at the $10 \%$ level of significance). This result suggests that especially for students with low elaborative explaining orientation, explanation expectancy caused state anxiety, because they do not know how to effectively prepare explanation. We must note, however, that in this study, participants were only required to write an explanation. Although Renkl (1995) did not clarify this point, the anxiety effect should be smaller with written explanation compared to oral explanation in the presence of another person. Therefore we did not consider that anxiety effect could fully explain the results of this study.

Our results revealed that the effect of explanation expectation depends on moderating variables, such as elaborative explaining orientation. Note, however, that assessing individual differences in metacognitive knowledge needs careful attention. In this study, we measured students' elaborative explaining orientation using self-reports. Previous research has indicated the effect of self-reported metacognitive knowledge on learning behavior and task performance (e.g., Mokhtari \& Reichard, 2002; Purdie et al., 1996). However, the validity of elaborative explaining orientation that was generated by the authors remains unclear. Therefore, it is suggested that more research should be conducted in the future on the relationships between elaborative explaining orientation and actual explaining behaviors.

In conclusion, this study highlights the need to acknowledge that elaborative explaining orientation exerts influences on the process of preparing an explanation, and possibly on the generating process as well. Peer tutors' elaborative explaining orientation might not only lead to bad explanations for tutees, but might hinder tutors' own learning by explaining. Thus, for a peer-tutorial program to be effective, administrators and classroom teachers need to focus on their students' elaborative explaining orientation. Considering that such knowledge plays an important role in the process of peer tutoring, a line of research examining teaching methods to promote learners' elaborative explaining orientation and accompanying learning gains would be a promising future direction.

\section{REFERENCES}

Aiken, L. S., \& West, S. G. 1991. Multiple regression: Testing and interpreting interactions. Newbury Park, CA: Sage.

Annis, L. F. 1983. The processes and effects of peer tutoring. Human Learning: Journal of Practical Research \& Applications, 2, 39-47.

Bargh, J. A., \& Schul, Y. 1980. On the cognitive benefits of teaching. Journal of Educational Psychology, 72, 593-604. 
Baron, R. M., \& Kenny, D. A. 1986. The moderator-mediator variable distinction in social psychological research: Conceptual, strategic, and statistical considerations. Journal of Personality and Social Psychology, 51, 1173-1182.

Benware, C. A., \& Deci, E. L. 1984. Quality of learning with an active versus passive motivational set. American Educational Research Journal, 21, 755-765.

Borkowski, J. G., Milstead, M., \& Hale, C. 1988. Components of children's metamemory: Implications for strategy generalization. In F. E. Weinert \& M. Perlmutter (Eds.), Memory development: Universal changes and individual differences (pp. 73-100). Hillsdale, NJ: Lawrence Erlbaum Associates.

Britton, B. K., \& Gülgöz, S. 1991. Using Kintsch's computational model to improve instructional text: Effects of repairing inference calls on recall and cognitive structures. Journal of Educational Psychology, 83, 329-345.

Cohen, J. 1969. The $t$ test for means. In J. Cohen (Ed.), Statistical power analysis for the behavioral sciences (pp. 17-71). New York: Academic Press.

Cohen, P. A., Kulik, J. A., \& Kulik, C. C. 1982. Educational outcomes of tutoring: A meta-analysis of findings. American Educational Research Journal, 19, 237-248.

Cromley, J. G., \& Azevedo, R. 2006. Self-report of reading comprehension strategies: What are we measuring? Metacognition and Learning, 1, 229-247.

Cronbach, L. J. 1987. Statistical tests for moderator variables: Flaws in analyses recently proposed. Psychological Bulletin, 102, 414-417.

Dart, B. C., Burnett, P. C., Purdie, N., Boulton-Lewis, G., Campbell, J., \& Smith, D. 2000. Students' conceptions of learning, the classroom environment, and approaches to learning. The Journal of Educational Research, 93, 262-270.

Efklides, A. 2011. Interactions of metacognition with motivation and affect in self-regulated learning: The MASRL model. Educational Psychologist, 46, 6-25.

Ehly, S., Keith, T. Z., \& Bratton, B. 1987. The benefits of tutoring: An exploration of expectancy and outcomes. Contemporary Educational Psychology, 12, 131-134.

Fiorella, L., \& Mayer, R. E. 2013. The relative benefits of learning by teaching and teaching expectancy. Contemporary Educational Psychology, 38, 281-288.

Flavell, J. H. 1979. Metacognition and cognitive monitoring: A new area of cognitive-developmental inquiry. American Psychologist, 34, 906-911.

Fukaya, T. 2013. Explanation generation, not explanation expectancy, improves metacomprehension accuracy. Metacognition and Learning, 8, 1-18.

Gunel, M., Hand, B., \& McDermott, M. A. 2009. Writing for different audiences: Effects on high-school students' conceptual understanding of biology. Learning and Instruction, 19, 354-367.

Ichikawa, S., Horino, M., \& Kubo, N. 1998. Gakushuhouhou wo sasaeru gakushukan to gakushudouki [Conceptions of learning and motivation that support learning skills]. In S. Ichikawa (Ed.), Ninchikaunseringu kara mita gakushuhouhou no soudan to shidou [Counseling and support for learning skills development from the perspective of cognitive counseling] (pp. 186-203). Tokyo: Brain Press. (In Japanese)

Ishii, T. 1997. Nihonjin no gijyutsu ha dokokara kitaka [Where does Japanese technology come from?]. Tokyo: PHP Interface. (In Japanese)

Ito, T., \& Kakihana, S. 2009. Why does explanation improve student tutors' understanding?: Effect of presence of a peer. Japanese Journal of Educational Psychology, 57, 86-98. (In Japanese with English abstract)

Kintsch, W. 1994. Text comprehension, memory, and learning. American Psychologist, 49, 294-303.

Mokhtari, K., \& Reichard, C. A. 2002. Assessing students' metacognitive awareness of reading strategies. Journal of Educational Psychology, 94, 249-259.

Pintrich, P. R. 2002. The role of metacognitive knowledge in learning, teaching, and assessing. Theory Into Practice, 41, 219-225.

Plötzner, R., Dillenbourg, P., Preier, M., \& Traum, D. 1999. Learning by explaining to oneself and to others. In P. Dillenbourg (Ed.), Collaborative learning: Cognitive and computational approaches (pp. 103121). Amsterdam: Pergamon.

Preacher, K. J., Curran, P. J., \& Bauer, D. J. 2006. Computational tools for probing interactions in multiple linear regression, multilevel modeling, and latent curve analysis. Journal of Educational and Behavioral Statistics, 31, 437-448. 
Pressley, M., \& Afflerbach, P. 1995. Verbal protocols of reading: The nature of constructively responsive reading. Hillsdale, NJ: Lawrence Erlbaum Associates.

Purdie, N., Hattie, J., \& Douglas, G. 1996. Student conceptions of learning and their use of self-regulated learning strategies: A cross-cultural comparison. Journal of Educational Psychology, 88, 87-100.

Renkl, A. 1995. Learning for later teaching: An exploration of mediational links between teaching expectancy and learning results. Learning and Instruction, 5, 21-36.

Roscoe, R. D., \& Chi, M. T. H. 2007. Understanding tutor learning: Knowledge-building and knowledgetelling in peer tutors' explanations and questions. Review of Educational Research, 77, 534-574.

Sakihama, H. 2003. The effects of writers' meta-cognitive knowledge and meta-cognitive activities on text production. Japan Journal of Educational Technology, 27, 105-115. (In Japanese with English abstract)

Samuelstuen, M. S., \& Bråten, I. 2007. Examining the validity of self-reports on scales measuring students' strategic processing. British Journal of Educational Psychology, 77, 351-378.

Schommer, M., Crouse, A., \& Rhodes, N. 1992. Epistemological beliefs and mathematical text comprehension: Believing it is simple does not make it so. Journal of Educational Psychology, 84, 435-443.

Solomon, J., Scott, L., \& Duveen, J. 1996. Large-scale exploration of pupils' understanding of the nature of science. Science Education, 80, 493-508.

Sugie, S., \& Kajita, M. 1989. The effects of teaching activities of children. Japanese Journal of Educational Psychology, 37, 381-385. (In Japanese with English abstract)

Suzuki, G. 2013. Grade-level differences in elementary and middle school students' conceptions of learning: Correlation with learning strategy use. Japanese Journal of Educational Psychology, 61, 17-31. (In Japanese with English abstract)

Toyama, S. 2003. Toyama Shigehiko chosakushyu 6 [The collection of Toyama Shigehiko. Vol.6]. Tokyo: Misuzu Press. (In Japanese)

Uesaka, Y. 2010. Metaninchi, gakushukan, gakushuhouryaku [Metacognition, conceptions of learning, and learning strategies]. In S. Ichikawa (Ed.), Gendai no ninchi shinrigaku Vol.5: Hattatsu to gakushu [Theories and Applications of Cognitive Psychology Vol.5: Development and Learning] (pp. 172200). Kyoto, Japan: Kitaohji Press. (In Japanese)

Uesaka, Y., Seo, M., \& Ichikawa, S. 2008. Students' cognitive and non-cognitive beliefs about learning as a factor in learning skills acquisition: Suggestions from cognitive counseling. In M. A. F. Silvester (Ed.), Transformations: Proceedings of the 2008 annual international conference of Association of Tertiary Learning Advisors Aotearoa New Zealand (ATLAANZ) (pp. 89-100). Auckland, New Zealand: ATLAANZ.

Weinstein, C. E., \& Mayer, R. E. 1986. The teaching to learning strategies. In M. C. Wittrock (Ed.), Handbook of research on teaching (pp. 315-327). New York: Macmillan.

(Manuscript received 20 June, 2013; Revision accepted 16 December, 2013) 


\section{Appendix A. Example of text}

Title: How are human beings affected by art?

When we listen to the same music, we are sometimes very impressed by it, but at other times we are not impressed. Similarly, the place where we sit in a music hall might make a difference to our impression of the same music. Therefore, the value of artistic work is not strictly fixed. There are no artistic works with values that are beyond time and place, because the value of every artistic work depends on how we think about it. The beauty of art happens when the work of art and the person truly interact. (Continued)

Appendix B. Example of memory and comprehension question

Part of verbatim memory tests (fill-in-blank tests)

1. Even if we listen to the same music, we sometimes are very [ ], but sometimes are not. ("Kanshin" in Japanese)

2. There are no artistic works with values that are [ ] time and place, ("Choetsu" in Japanese)

Part of comprehension tests (multiple-choice tests)

1. Which of the following would most likely fit the author's claim?

a. The music we have listened to many times makes us tired.

b. Because the value of every artistic work depends on how we think about it, we should develop an impressionable mindset.

c. The value of artistic work is not strictly fixed, and it depends on the educational background of the audience.

d. Where we sit in a music hall might make a difference to our impression of the same music, because we cannot see our favorite musicians from certain seats.

e. Even when we listen to the same music played by great musicians, we are moved, but when played by average musicians, we are not.

f. Because our state of mind changes, the same music does not always give us the same impression. (Correct answer) 